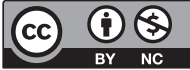

\title{
Entre visível e invisível, para além do entendimento: o tema da natureza no último Merleau-Ponty
}

\author{
Between visible and invisible, beyond \\ understanding: the concept of nature in \\ Merleau-Ponty's last work
}

\section{Paula Mousinho Martins}

Doutora em Filosofia pela Universidade Federal do Rio de Janeiro (UFRJ), professor associado da Universidade Estadual do Norte Fluminense Darcy Ribeiro, Rio de Janeiro, RJ - Brasil, e-mail: pmartins@uenf.br

\section{Resumo}

Merleau-Ponty dedica-se ao tema da natureza a partir de meados da década de 1950, quando sua crítica à "filosofia do entendimento", sobre a qual o pensamento operatório da ciência está fundado, leva-o à revisão radical das categorias com as quais o ser natural era tradicionalmente tratado. A investigação do conceito de natureza surge como "propedêutica" para uma autêntica ontologia, tendo um importante papel na superação dos pressupostos "reflexionantes" da fenomenologia. Redescobrir a natureza como 
"solo", mantendo-a aquém da antinomia realismo/idealismo, exige dissolver a ideia que funda a própria antinomia: o ser como "plenitude absoluta" ou "infinita positividade", segundo a qual o ser ou bem comporta tudo, ou então não é nada. Esse trabalho, que marca o último período da vida do filósofo, distingue-se pela reação à ideia de negatividade presente em seus próprios escritos anteriores, mas também no pensamento francês de sua época, especialmente o de Sartre. O caráter antitético ou contraditório da oposição ser/nada será combatido pela análise das categorias (não alternativas) de visível e invisível, que o filósofo explorará sobretudo no âmbito da experiência pictórica, nele encontrando um importante suporte para sua reflexão ontológica.

Palavras-chave: Natureza. Fenomenologia. Ontologia.

\section{Abstract}

Merleau-Ponty starts to focus on the concept of nature from the middle of the 1950s, when his criticism of the "philosophy of understanding", which the operative thinking of science is based on, leads him to criticize nature's traditional categories. The investigation of the concept of nature turns out to be a necessary introduction to an authentic ontology, since it plays an important role in the overcoming of the reflective phenomenological standpoint. Recognizing nature as "soil" means keeping it beneath the realism/idealism antinomy, which in turn requires surmounting the antinomy's founding idea of being as an "absolute plenitude" or an "infinite positive". Following this idea, being is either everything or nothing. This work, which attracted the author's attention during the last period of his life, is characterized by the reaction against the idea of negativity developed by some French philosophers of his time, especially Sartre. The contradictory character of the being/nothing opposition will be combated by the analysis of the non-alternative categorical couple visible and invisible, which the painting experience constitutes an important ontological support to.

Keywords: Nature. Phenomenology. Ontology. 


\section{Introdução}

Há uma "crise de racionalidade" nas relações das ciências naturais com seu objeto de estudo - escreve Merleau-Ponty em 1959-, cujo teor reflete a lógica de sua própria evolução técnica (MERLEAU-PONTY, 1996, p. 23). Essa lógica, "que reduz o ser à alternativa e à antinomia do em si do puro objeto e do artefato" (MERLEAU-PONTY, 1996, p. 44), revela-se duplamente falsa: em sua afirmação da natureza e em sua negação da natureza (MERLEAUPONTY, 1996, p. 43). No primeiro caso, a natureza é afirmada como causa universal em si e como tal preexiste às ciências, que se limitam a perseguir-lhe as articulações; no segundo, tem-se em vista o condicionamento do conceito de ser natural pela história e a cultura humanas (MERLEAU-PONTY, 1996, p. 43). A proposta de Merleau-Ponty para superar tal crise é conhecida: cumpre redescobrir a natureza como solo (MERLEAU-PONTY, 1996, p. 44), mantendo-a aquém do dilema tradicional que ora a remete à ordem realista do puro acontecimento (sem medida comum com nosso pensamento), ora a vê como constructo inteligível cujas ligações constitutivas a reflexão idealista enumera e explicita. Atrás da oposição entre realismo e idealismo, pensa o filósofo, esconde-se na verdade uma estreita cumplicidade, os dois lados não sendo senão expressões tardias de um único e mesmo pressuposto que, de resto, orienta a filosofia do entendimento desde sua origem: a ideia do ser como plenitude absoluta ou absoluta positividade, segundo a qual o ser ou bem comporta tudo, $o u$ então não é nada (MERLEAU-PONTY, 2000, p. 206-207). À luz desse paradigma inaugural, o que é não se mescla ao que não é.

\section{Desenvolvimento}

A compreensão moderna do ser natural como "objeto em si", vale dizer, como "um ser que é o que é porque não pode ser outra coisa", é obviamente tributária dessa ideia prévia de um ser sem restrição (infinito ou causa de si), que por sua vez emerge da suposição de uma alternativa (e, portanto, de uma antinomia absoluta) entre o ser e o nada (MERLEAU-PONTY, 1968, p. 99). Graças a essa metafísica avessa a misturas e mediações, a física e a psicologia puderam definir suas áreas de atuação: tendo retirado "escrupulosamente" da subjetividade humana todas as propriedades das coisas, a filosofia do entendimento acabou por instaurar, no lugar do nada, a "confusa" e "laboriosa" história da psyché (MERLEAU-PONTY, 1996, p. 362). O moderno 
conceito de natureza nasce, pois, sob a égide de uma "mitologia bastarda" (MERLEAU-PONTY, 1996, p. 361), de acordo com a qual, se as coisas formam um mundo porque estão em relação de contiguidade e ação recíproca, resta aos "espíritos flutuarem aqui e acolá sobre este mundo pleno como ilhas de negatividade", as quais a noção de "mundo objetivo", se bem entendida, incessantemente ameaça “contaminar" (MERLEAU-PONTY, 1996, p. 44). Este e outros paradoxos advirão dessa atitude purificadora da filosofia do entendimento (MERLEAU-PONTY, 2000, p. 206), ${ }^{1}$ que a impede de pensar algum tipo de cruzamento entre o ser e o não-ser, mas simultaneamente a condena a só poder conceber um lado trazendo a reboque o pensamento do outro.

Semelhante filosofia é necessariamente trabalhada pela dúvida e por um certo estrabismo. [...] Esse estrabismo é visto com a maior nitidez no dilema do ser e do nada presente por toda parte no horizonte do pensamento de Descartes. [...] Essa filosofia é minada pela referência a um nada do qual ela afirma incessantemente que não é, mas sobre o qual não para de pensar. (MERLEAU-PONTY, 2000, p. 206). ${ }^{2}$

Para restituir à natureza seu devido sentido, é preciso então, em primeiro lugar, libertá-la da definição de extensão como positividade pura e de sua contra-abstração: a noção de espírito como negação da extensão. Merleau-Ponty lança-se a essa tarefa a partir de meados da década de 1950, ao constatar que uma ontologia do ser natural se fazia urgente como "propedêutica" (MERLEAU-PONTY, 2000, p. 265) para uma autêntica ontologia. A intenção era antes de tudo radicalizar a crítica - ainda insuficientemente elaborada no período da Fenomenologia da percepção - às categorias com as quais as ciências e a filosofia haviam se acostumado a pensar a natureza: a identidade, a causalidade, a sucessão e o espaço homogêneo. Mais do que isso, Merleau-Ponty punha radicalmente em xeque a própria ideia de substância ao tratar o negativo não em oposição ao ser natural, mas como condição de sua "espessura" e "profundidade". O propósito era devolver à natureza as

1 “É próprio de uma filosofia do entendimento só querer tomar por tema aquilo que obtém por um processo de purificação. Tudo que precede a isto é rejeitado para a sombra" (MERLEAUPONTY, 2000, p. 206).

2 O autor continua: "Descartes diz que, quando pensa o ser, é de imediato no ser infinito que ele pensa, e isto porque a noção de ser comporta tudo ou não comporta nada" (MERLEAUPONTY, 1984, p. 206.) 
"graduações" e a "pluralidade de planos" que lhe haviam sido extraídas desde que passou a ser vista como "um ser que, para ser positivo e pleno, deveria ser plano" (MERLEAU-PONTY, 1984, p. 73). Nada disto será possível, todavia, sem uma completa "destruição das idealizações" - dos "ídolos" (MERLEAUPONTY, 1996, p. 362) cujo exemplo mais notável é a determinação da extensão como positividade pura e do espírito como negatividade pura -, no termo da qual poderá empreender-se o retorno ao estado de "indivisão entre ser e nada que nós mesmos somos, e de algum modo conhecemos bem, pois que desde sempre o vivenciamos" (MERLEAU-PONTY, 1996, p. 362). Uma vez abandonada a definição do espírito como negação de todas as características das coisas, e das coisas como puramente coisas desprovidas de valor ou qualidade, subsistirá a certeza de que ambos, espírito e coisa, pertencem a um mesmo mundo (MERLEAU-PONTY, 1984, p. 73).

O primeiro passo na consecução desses objetivos será, portanto, afastar a interpretação matemática da natureza como planaridade inerte jacente absolutamente em si, por toda parte igual a si, sem fissura ou antagonismo, clara e manejável, destituída de latência e virtualidade. Consequentemente, repudiar a ideia euclidiana de um ser-objeto independente de todo ponto de vista ou envolvimento, um ser meramente "projetivo" e "horizontal" que só pode permanecer o que é fora do terreno fragmentário e ambíguo em que estamos concretamente confinados. Eis então o único sentido de natureza passível de ser ontologicamente interrogado: o de que estamos nela e não "diante" dela.

Essa nova ontologia da natureza que não mais condiz com as "ontologias do algo", e por isso descarta a figura de um ser logicamente necessário surgindo ex-nihilo como presença plenamente positiva contra o fundo absoluto do nada, tem em vista um ser não-parmenidiano capaz de escapar ao dilema do ser e do não-ser: um ser que, não se contrapondo ao nada, não the seja todavia "indiscernível” (MERLEAU-PONTY, 1984, p. 73). Tal ontologia recusa-se a justapor o nada ao ser como uma substância distinta para não inoculá-lo de positividade, mas ao mesmo tempo em que constata que ser e nada não podem formar um conjunto de contíguos, compreende que o nada deve discernir-se do ser a fim de preservar sua nulidade constitutiva. Só não se discerne o ser do nada quando, partindo-se da determinação do primeiro como uma totalidade absolutamente positiva, há que se lidar com a tendência inexorável de seu oposto imediato, o nada absoluto, de exigir para si a escala infinita do ser. Um ser absolutamente positivo só pode ser ele mesmo em contraste com o absolutamente negativo, mas este, graças à sua nulidade intransponível, vem apenas corroborar a infinita positividade de seu contrário, levando-se em 
conta que nada os distingue. Lutar contra essa vocação inalienável do nada de exaurir a totalidade de seu inverso só pode redundar numa vã tentativa de totalização teórica: toda vez que se tenta dimensionar o ser de modo absoluto e positivo, é inevitável ver surgir a figura imperiosa, conquanto indesejada e paradoxal do nada, "não à margem ou em alguma zona de não-visão, mas em toda a extensão do que vemos como aquilo que a instala" (MERLEAUPONTY, 1984, p. 73).

Rejeitar a tese da indiscernibilidade do ser e do nada não significa, portanto, postular sua diferença irredutível, mas aceitar que a força do ser se apoia na fraqueza de seu adversário e cúmplice, o não-ser, de sorte que opôlos de forma absoluta só pode consistir num procedimento abstrato e superficial: o ser puro sem restrição, assim como o nada absoluto, é inencontrável.

Segue-se que o célebre problema ontológico por que há ser em vez de nada desaparece com a alternativa: não há algo ao invés de nada já que o nada não poderia tomar o lugar do ser. $\mathrm{O}$ nada inexiste em sentido negativo ao passo que o ser é. Tudo é obscuro quando não se pensou o negativo, tudo é claro quando pensado como negativo (MERLEAU-PONTY, 1984, p. 73).

Mas é todo um outro pensamento do negativo, distinto daquele que governava os dualismos, que é preciso agora desenvolver. Um pensamento que seja antes de tudo capaz de reconhecer que o nada é relativo ao ser como o direito é relativo ao avesso, daí não se poder falar nem de um nem do outro como idênticos a si mesmos. Se afirmar o que o negativo é destrói sua negatividade, supor que ele simplesmente não é igualmente o conduz à positividade: ambas as atitudes fazem do negativo um "objeto" e com isso dirimem sua força negativa; transformando-o numa "essência", fixam seu poder de furtarse e eludir. Porquanto ainda é muito dizer do nada simplesmente que não é, que é pura negação, dando expressão àquilo que, a rigor, "não tem nome, nem repouso ou natureza" (MERLEAU-PONTY, 1984, p. 90).

Nesse sentido, tanto o pensamento do "negativo puro" quanto o do "positivo puro", em sua tendência comum a tomar por tema apenas aquilo que obtêm por purificação, revelam-se maneiras igualmente positivistas de pensar. Quando, a partir do nada, proclamam que não há senão ser, afastam-se do concreto, desconsideram as articulações do todo, compensam uma abstração com uma contra-abstração. Todo o poder da negatividade não passará então de mero "prurido" na superfície do ser enquanto este último excluir de si o não-ser em todas as suas dimensões: seja o poder-ser que ainda não é do 
futuro, seja o tornar-se o que não é do movimento e da mudança, seja o já não é mais que caracteriza o passado. O problema da negatividade desdobra-se, assim, nos problemas do movimento e da temporalidade, vindo reforçar a crítica merleau-pontyana da formulação tradicional do possível como conjunto de determinações estranhas à realidade.

Se, reduzido a si mesmo, o negativo nada quer dizer, o positivo sozinho também nada diz, e no fim das contas os dois mostram-se sinônimos: dá no mesmo dizer que o nada não é e que há apenas ser. Pensar cada um dos opostos como a ausência ou a impossibilidade do outro redunda em compreendê-los como idênticos, e o único meio de sair deste impasse criado pelo entendimento será aceitar que o ser e sua negação não constituem instâncias alternativas nem contraditórias. Nessa perspectiva, princípios tais como "o ser é e o nada não é" ou "há tão somente ser", que o entendimento considera irredutíveis, revelam-se na realidade fórmulas derivadas de uma ordem prévia e unívoca de verdade, calcada no imperativo da identidade que obriga os opostos a repelirem-se mutuamente e jamais se interpenetrarem.

Afastado o ponto de partida de um ser exclusivamente afirmativo e, portanto, essencialmente obstativo ao vácuo infinito do nada, descortina-se o terreno que realmente interessa à investigação ontológica, a saber: o campo de aparências (MERLEAU-PONTY, 1984, p. 90) em que se trava o jogo da reversibilidade entre ser e não-ser. Segundo as regras deste jogo, toda vez que a aparência de um é tomada à parte, tende a estilhaçar-se para ser prontamente substituída pela aparência do outro. Mas o jogo ele mesmo ainda não é a última instância ontológica porque ainda possui um horizonte: o "meio comum onde ser e nada, que são apenas lékta, trabalham um contra o outro" (MERLEAU-PONTY, 1984, p. 73). ${ }^{3}$

Eis o tema crucial de $O$ visivel e o invisivel e também a razão de sua ruptura com a Fenomenologia da percepção: o ser é túrgido de não-ser e de possível; não é apenas aquilo que é. Em outras palavras, ser não significa permanecer na identidade. Embora a obra de 1945 já enunciasse a crítica ao caráter exclusivamente antitético do ser e do nada, persistia-lhe a inclinação de situar a temporalidade, a possibilidade e a negação do lado do sujeito, isto é, do lado oposto à totalidade do ser material (MERLEAU-PONTY, 1999). ${ }^{4}$

3 Grifo nosso.

4 "O passado e o porvir, por si mesmos, retiram-se do ser e passam para o lado da subjetividade para procurar nela não algum suporte real, mas, ao contrário, uma possibilidade de não-ser que se harmonize com sua natureza. [...] É essencial ao tempo fazer-se e não ser, nunca estar 
Essa complacência do jovem Merleau-Ponty à maneira de proceder típica da fenomenologia husserliana - contrapor uma consciência temporalizada a uma realidade extensa esvaziada de tempo e negatividade - vai sendo, no entanto, abandonada à medida que a exigência ontológica de ultrapassar a oposição abstrata entre o ser (visível) e o nada (invisível) é assumida de modo integral.

Esse trabalho, que consome o último período da vida do filósofo, é marcado pela reação à ideia de negatividade dominante não só em seus próprios escritos anteriores, mas também no pensamento francês de sua época, de Kojève a Sartre: a compreensão do negativo como consciência ou subjetividade, ou, segundo a formulação sartreana, como zona "pré-reflexiva" de abertura ao ser em oposição à positividade indiferente do ser em si mesmo. No pensamento de Sartre, essa abertura só é possível desde que nada possa interpor-se entre a subjetividade e o ser - daí a obrigatoriedade de desvencilhar o ser-sujeito dos fantasmas com que a tradição o entulhou: "representação", "pensamento", "imagem", ou mesmo "sujeito", "espírito" ou "ego", nada disso permanecerá retendo-me em mim mesmo e me afastando das coisas. Se, depois disso, ainda persiste uma "subjetividade" na ontologia fenomenológica de Sartre, ela deve ser compreendida como "inexistência pura": um ser absoluto, embora nãosubstancial, que é puramente translúcido para si mesmo e imediatamente aberto ao mundo em sua plenitude e positividade. Enquanto transparência, espontaneidade e reflexividade puras, a consciência pode, de fato, ser reduzida a nada, isto é, a uma pura "presença a si" sem matéria ou extensão que só pode ser o que é negando-se a si mesma. ${ }^{5}$

O caráter negativo da consciência sartreana demanda, assim, a posição de um ser que a transcenda absolutamente; desprovida em si mesma de ser ou positividade, ela terá o mundo como único suporte ontológico. A consciência é, pois, essencialmente mundana, e esta característica imprescindível a diferencia de um "cogito substancial". Contrariamente ao idealismo reflexionante que fechava a consciência sobre si mesma, Sartre a põe integralmente fora de si: sua imanência é a sua própria transcendência. Dado que enquanto

completamente constituído. [...] Portanto, o passado não é passado, nem o futuro é futuro. Eles só existem quando uma subjetividade vem romper a plenitude do ser em si, desenhar ali uma perspectiva, ali introduzir o não-ser" (MERLEAU-PONTY, 1999, p. 552-564).

5 "Le champ transcendantale, purifié de toute structure égologique, recouvre sa limpidité première. En un sens c'est un rien puisque tous les objets physiques, psycho-physiques et psychiques, toutes les vérités, toutes les valeurs sont hors de lui, puisque mon Moi a cessé, lui même, d'en faire partie. Mais ce rien est tout , puisque il est conscience de tous ces objets" (SARTRE, 1982, p. 74).

Rev. Filos., Aurora, Curitiba, v. 22, n. 31, p. 469-482, jul./dez. 2010 
nada ela não se distingue daquilo que não é, a consciência confunde-se com a própria permanência do ser. Caso do ser se diferenciasse, o nada seria alguma coisa, isto é, perderia sua nulidade constitutiva, o que leva Sartre a concluir que o nada não é senão o próprio ser. O negativo puro, negando-se a si mesmo, sacrifica-se ao positivo; o positivo puro, enquanto se afirma sem restrição, sanciona esse sacrifício. Ser e nada se identificam e, desta maneira, a visão do ser como um não-eu absoluto repousando sobre si mesmo surge como sinônima da visão de um "si" que é puro vácuo, ausência de ser. Já que o nada é o que não é - quer dizer, não é atributo, nem função, nem acidente do ser - não há senão ser. O para si, por sua negação de si, torna-se a mais pura afirmação do em si (MERLEAU-PONTY, 1984, p. 60). Negando-se a si mesma, a negatividade pura lança o ser na positividade absoluta, com a qual se identifica.

Neste seu afã de "descoisificar" a consciência para reintegrá-la no mundo, Sartre acaba, como se vê, pagando tributo à mesma metafísica substancialista que pretendia criticar. Embora invertendo o modus operandi da filosofia reflexionante - que inscrevia toda a positividade no "interior" do sujeito, tratando o "exterior" como negatividade -, Sartre obstrui da mesma forma qualquer encontro ou "fricção" entre o mundo e o sujeito, já que um é ser e o outro nada é. Antinatureza que sou, encerro-me em mim mesmo absolutamente estranho ao ser natural que permanece pacífica e obstinadamente ele mesmo, onticamente inerte, sem rupturas ou descontinuidade internas. Quanto a mim, sujeito percepiente, habito alguma vizinhança infinitamente distante desse "objeto em geral" que não me perturba nem altera. Na posição de um nada que interroga, parto de um fundo infinito de onde percebo a totalidade das coisas em absoluta equidistância; destituído de qualquer aderência carnal ao mundo, deste posso apenas construir um "pensamento".

Diferentemente de Sartre, o autor de $O$ visivel e o invisível recusa-se a partir da oposição imediata do em si e do para si porque para ele a segregação entre ambos jamais estará inteiramente acabada. Rejeitando descrever nosso relacionamento com o mundo a partir de uma abertura do nada ao ser porque esta já supõe a oposição entre ambos, Merleau-Ponty prefere traduzi-lo como a abertura a partir da qual se pode compreender ser e nada, em si e para si. O pensamento do último Merleau-Ponty começa justo onde o de Sartre termina, como explica uma nota de trabalho da célebre obra inacabada:

Meu ponto de partida está onde Sartre tem seu ponto de chegada, no ser retomado pelo para si - Este é seu ponto de chegada porque ele parte do 
ser e da negatividade e constrói sua união. Para mim é a estrutura ou transcendência quem explica, e o ser e o nada (no sentido de Sartre) são duas propriedades abstratas (MERLEAU-PONTY, 1984, p. 60).

O desdobramento das diferenciações entre ser e nada, visível e invisível, está em devir permanente e um dos deveres da tarefa pós-fenomenológica de Merleau-Ponty será acompanhar tal processo na dinâmica mesma de suas não-coincidências e reconciliações. Em Sartre, como vimos, a oposição previamente estabelecida ao ser induzia o suicídio do para si: levando a negação para além do ser como subjetividade absoluta, Sartre identificava os opostos e inviabilizava qualquer trâmite genuinamente dialético entre ser e nada. Problema semelhante é detectado no próprio Hegel, que também recorre à imagem ambivalente de um nada que se sacrifica para que o ser seja - e de um ser que, do alto de sua primazia absoluta, "tolera" esse reconhecimento da parte do nada (MERLEAU-PONTY, 1984, p. 94-95). É preciso prevenir-se, enfim, contra a armadilha de transformar a dialética num "princípio explicativo", isto é, converter seu movimento concreto em "significação", embalsamando-o sob "uma lei e um quadro exterior ao conteúdo" (MERLEAUPONTY, 1984, p. 216).

Segue-se que quando Merleau-Ponty fala de uma indivisão entre ser e nada, não está decerto se referindo a alguma "vaga mistura" dos dois termos, mas tampouco quer aludir a uma "síntese dialética superior": entendida como "supressão absoluta de si mesma por si mesma", a operação sintética correria o risco de recair na abstração positiva, aniquilando-se num mero quadro exterior ao conteúdo. Acrescente-se que a síntese dialética mostra-se estranha ao próprio movimento da vida e da história, que conhecem apenas superações parciais - com seus déficits e ambiguidades -, mas jamais a "superação de todos os aspectos que simultaneamente conserva tudo o que as fases precedentes adquiriram" (MERLEAU-PONTY, 1984, p. 96). Entre os inúmeros desafios de uma autêntica ontologia está, pois, o de trilhar o caminho da boa dialética, o qual, desdobrando-se aquém da clivagem reflexiva "em si versus para si", diferencia e integra não apenas dois mas múltiplos sentidos, precisamente porque se inscreve numa "totalidade de horizonte que não é síntese" (MERLEAU-PONTY, 1984, p. 197), que é pregnância do nada no ser, Urstiftung e não simples subsunção (MERLEAU-PONTY, 1984, p. 195). Tal totalidade "abunda no mundo sensível sob a condição de que este seja despojado de tudo o que as ontologias lhe acrescentaram" (MERLEAU-PONTY, 1984, p. 93). 


\section{Considerações finais}

A crítica à incapacidade do pensamento reflexivo, a tensão que empurra o filósofo para além da fenomenologia, a reabilitação do sensível como meio de o ser se manifestar sem tornar-se positividade, finalmente, a exigência de elaborar uma nova ontologia da natureza em que a oposição absoluta do ser e do não-ser esteja por fim colocada em questão: essas e outras facetas que marcam a obra tardia de Merleau-Ponty devem-se muito à sua meditação sobre a pintura. Como notou Claude Lefort (MERLEAU-PONTY, 2004, p. 12), a análise das contradições que minaram a filosofia do entendimento provém em grande parte da observação dos paradoxos que animam a expressão, a arte e a pintura em particular. Alguns aspectos da análise merleaupontyana da experiência pictórica efetivamente iluminam a copertinência entre visível e invisível que o filósofo tanto buscou revelar nos últimos anos de sua vida.

Imaginária e real, essência e existência, a pintura de fato confunde as categorias do entendimento ao instanciar um tipo de ser que não é da ordem do em si, mas tampouco pode reduzir-se ao nada que define o domínio espiritual. Por isso Merleau-Ponty equipara a pintura a uma autentica ontologia, à qual retorna várias vezes ao longo de sua obra, e particularmente no último ensaio concluído antes de morrer, "O olho e o espírito", no qual não por acaso aprofunda a crítica às filosofias da subjetividade - aí incluído o sujeito perceptivo da Fenomenologia da percepção.

Para começar, a experiência pictórica é a prova por excelência de que a visibilidade "comporta" a invisibilidade - não como outra visibilidade possível, ou como um possível visível para outro, quer dizer, não como um objeto não visto, positividade situada alhures, mas como outra dimensão, em uma palavra, negatividade. Não a negatividade lógica ou contraditória, bem entendido, mas a negatividade como verticalidade e profundidade do visível: meio que as coisas possuem de permanecer nítidas para, "embora não como aquilo que olho atualmente", fazerem-se coisas (MERLEAU-PONTY, 1984, p. 203). ${ }^{6} \mathrm{O}$ maior enigma do pintor é exatamente esse invisível que medeia e liga as coisas, é neste âmbito que ele intenciona flagrar a própria estrutura da visão: sua experiência leva à última potência a espécie de "delírio" em que a própria visão em geral consiste - afinal, ver é um estranho "ter à distância” -

\footnotetext{
6 "Através da profundidade, as coisas coexistem cada vez mais intimamente, deslizam umas nas outras e se integram” (MERLEAU-PONTY, 1984, p. 203).
} 
e é essa curiosa "posse" que o pintor quer franquear a todos os aspectos do ser (MERLEAU-PONTY, 2004, p. 20).

Nesta sua tarefa de ampliar a visibilidade, estendendo-a inclusive aos meios pelos quais a própria pintura se realiza, o pintor almeja que tudo se torne visível a partir de uma visão que se faz do meio das coisas (e não diante de ou sobre elas) - lá onde habita a indivisão do sentiente e do sentido. O olhar do pintor não pode, portanto, ser reduzido a uma relação físico-óptica com o mundo, nem este pode estar diante do pintor por mera representação: é o pintor que nasce no meio das coisas como por concentração e vinda a si do visível.

Como todo vidente, o pintor está imerso no mundo por um corpo que é ele mesmo visível, mas não enquanto "porção" do espaço; sua visão depende do movimento desse corpo, razão pela qual o olhar do pintor jamais se "apropria" do visível, apenas dele se aproxima. Por ter ele mesmo um corpo, o pintor não pode eximir-se de sua própria visibilidade para os outros - daí tantos pintores terem dito que "as coisas os olham" em vez de serem olhadas por eles (MERLEAU-PONTY, 2004, p. 22). As coisas pintadas não pressupõem o olhar do pintor, já que este é feito da mesma "carne" que elas; não é o artista quem as cria, e sim o ser que se recria em produto por meio do videntevisível. O espetáculo visível pertence ao corpo do pintor tanto quanto suas "qualidades tácteis", mas isto não significa que sejam campos coextensivos. Há uma topografia dupla e cruzada do visível no tangível e do tangível no visível que a experiência da pintura potencializa, mas os dois "mapas" em si mesmos são completos, não se confundem nem se justapõem (MERLEAUPONTY, 1984, p. 131).

Nada mais distante do que postulava a Dióptrica de Descartes, ao tomar a pintura por um palco de "ilusões" ou "percepções sem objeto" à margem de uma "natureza sem equívoco" (MERLEAU-PONTY, 2004, p. 24). Um quadro para Descartes nada mais é que uma coisa plana que artificiosamente representa aquilo que veríamos em presença de coisas diversamente reveladas: por mais vivamente que nos ofereça as coisas, o quadro em si mesmo não se lhes assemelha verdadeiramente, é apenas um pouco de tinta sobre uma superfície, para além da qual o pensamento é convidado a "enxergar" a coisa representada. Dado que não podemos encontrar a imagem pintada no "interior" dos olhos ou no cérebro, o pensamento funcionaria então como uma "visão sutilizada da imagem" (MERLEAU-PONTY, 2004, p. 25). Em outros termos, porque a visão é o pensamento em sua função de decifrar os signos dados na matéria corporal (sem qualquer promiscuidade entre o vidente e o visível), o quadro não passa de um "texto" proposto à nossa leitura, que carece dos 
“olhos do cérebro" para ser decodificado (MERLEAU-PONTY, 2004, p. 25). A “visão" filosófica, capaz de "enxergar" para além das aparências, tem todas as razões para não mais frequentar o visível, incumbindo-se de reconstruí-lo "segundo o modelo que dele se oferece" (MERLEAU-PONTY, 2004, p. 24). Assim se erige o "pensamento de ver", próprio à tradição cartesiana, que deduz modelos para a visão, mas falha em apreender a experiência visual em sua concretude e originalidade.

Ora, a visão não é um determinado modo do pensamento ou "presença a si" do sujeito vidente; ela é o meio que me é dado de me "ausentar de mim mesmo" a fim de assistir "por dentro" às fissões ou segregações do ser. Daí por que Merleau-Ponty se interessa tanto pela ontologia da visão, nela encontrando "um desafio real à analítica do ser e do nada, da existência como consciência e da existência como coisa - que exige uma reconstrução completa da filosofia" (MERLEAU-PONTY, 1984, p. 183). A experiência do pintor nada mais é que a radicalização desse olhar que não "decifra", "pensa", "projeta" ou "interpreta" as coisas sensíveis, senão as envolve, apalpa e esposa (MERLEAU-PONTY, 2004, p. 130), e desta forma é o inverso do olhar reflexionante que prefere ver como a visão se produz a aderir a ela. Muito além da metáfora, da ilusão ou da simples analogia - longe de uma percepção sem objeto "o mais parecida possível” com a percepção com objeto que caracteriza a percepção empírica (MERLEAU-PONTY, 2004, p. 170)-, a pintura é antes uma interrogação do olhar à coisa que tem por fim desvendar "como a coisa se faz coisa e o mundo se faz mundo" (MERLEAU-PONTY, 2004, p. 170). A visão do pintor só aprende vendo, só aprende por si mesma, e o que ela aprende, e tem por obrigação explorar, é que ver já é como realizar uma obra de arte. Há sem dúvida uma arte de ver sediada em todo corpo vidente que se apreende como visível (TASSINARI, 1989, p. 29).

\section{Referências}

MARTINS, P. M. Natureza, tempo e movimento: Merleau-Ponty leitor de Whitehead. O que nos faz pensar, Cadernos do Departamento de Filosofia da PUC-Rio, v. $25,2009$.

MERLEAU-PONTY, M. Resumés de cours. Collège de France 1952-1960. Paris: Gallimard, 1968.

MERLEAU-PONTY, M. O visível e o invisível. São Paulo: Perspectiva, 1984. 
MERLEAU-PONTY, M. Notes de cours 1959-1961. Paris: Gallimard, 1996.

MERLEAU-PONTY, M. Fenomenologia da percepção. São Paulo: Martins Fontes, 1999.

MERLEAU-PONTY, M. A natureza. São Paulo: Martins Fontes, 2000.

MERLEAU-PONTY, M. O olho e o espírito. São Paulo: Cosac \& Naify, 2004.

SARTRE, J-P. L'être et le néant. Paris: Gallimard, 1971.

SARTRE, J-P. La transcendence de l'Ego. Paris: Vrin, 1982.

TASSINARI, A. Filosofia, visão e pintura: estudo sobre a filosofia da pintura de Merleau-Ponty. 1989. Dissertação (Mestrado em Filosofia) - Universidade São Paulo, São Paulo, 1989.

Recebido: 10/06/2010

Received: 06/10/2010

Aprovado: $15 / 09 / 2010$

Approved: 09/15/2010 